\title{
Structural and Functional Maturation of Cardiomyocytes Derived from Human Pluripotent Stem Cells
}

\author{
Scott D. Lundy, ${ }^{1,2}$ Wei-Zhong Zhu,,$^{2,3}$ Michael Regnier, ${ }^{1,2,4}$ and Michael A. Laflamme ${ }^{2,3,4}$
}

\begin{abstract}
Despite preclinical studies demonstrating the functional benefit of transplanting human pluripotent stem cellderived cardiomyocytes (PSC-CMs) into damaged myocardium, the ability of these immature cells to adopt a more adult-like cardiomyocyte (CM) phenotype remains uncertain. To address this issue, we tested the hypothesis that prolonged in vitro culture of human embryonic stem cell (hESC)- and human induced pluripotent stem cell (hiPSC)-derived CMs would result in the maturation of their structural and contractile properties to a more adult-like phenotype. Compared to their early-stage counterparts (PSC-CMs after 20-40 days of in vitro differentiation and culture), late-stage hESC-CMs and hiPSC-CMs (80-120 days) showed dramatic differences in morphology, including increased cell size and anisotropy, greater myofibril density and alignment, sarcomeres visible by bright-field microscopy, and a 10-fold increase in the fraction of multinucleated CMs. Ultrastructural analysis confirmed improvements in the myofibrillar density, alignment, and morphology. We measured the contractile performance of late-stage hESC-CMs and hiPSC-CMs and noted a doubling in shortening magnitude with slowed contraction kinetics compared to the early-stage cells. We then examined changes in the calciumhandling properties of these matured $\mathrm{CMs}$ and found an increase in calcium release and reuptake rates with no change in the maximum amplitude. Finally, we performed electrophysiological assessments in hESC-CMs and found that late-stage myocytes have hyperpolarized maximum diastolic potentials, increased action potential amplitudes, and faster upstroke velocities. To correlate these functional changes with gene expression, we performed qPCR and found a robust induction of the key cardiac structural markers, including $\beta$-myosin heavy chain and connexin-43, in late-stage hESC-CMs and hiPSC-CMs. These findings suggest that PSC-CMs are capable of slowly maturing to more closely resemble the phenotype of adult CMs and may eventually possess the potential to regenerate the lost myocardium with robust de novo force-producing tissue.
\end{abstract}

\section{Introduction}

$\mathrm{T}$ HE LOSS OF VIABLE MYOCARDIUM due to ischemic or other pathologic insult often leads to insufficient cardiac performance to maintain end-organ perfusion, a condition known as heart failure. Cell therapy represents a promising strategy to halt or reverse the progression of this disease, and a number of candidate cell types have been investigated in both preclinical and clinical studies with mixed success [1-4]. Pluripotent stem cell-derived cardiomyocytes (PSC-CMs), including human embryonic stem cell (hESC)-derived- and human induced pluripotent stem cell (hiPSC)-derived cardiomyocytes (CMs), offer a number of advantages for cell-based cardiac repair, but most in vivo studies as of yet have shown only partial or transient restoration of contractile function [5-8]. One potential explanation is the underdeveloped contractile properties of PSC-CMs, which lack the robust contractile machinery found in mature adult CMs and instead resemble primitive CMs [9-14]. Even if PSC-CMs successfully engraft in the infarcted heart, it seems unlikely that in their current form, they possess the ability to replace the forcegenerating capacity of the mature myocardium lost during the initial insult. On the other hand, it is possible that enhancing the force production capabilities of PSC-CMs could result in a more robust and permanent improvement in cardiac function after cell transplantation.

A number of recent studies have examined the maturation of PSC-CMs toward the adult phenotype [11,15-17], but the majority of these studies have focused primarily on electrophysiological endpoints. While these reports have demonstrated that hESC-CMs are capable of some degree of phenotypic maturation, it remains to be seen whether comparable improvements in the structural and contractile properties are possible. Additionally, while some initial efforts to characterize hESC-CM contractility have been performed, they have primarily focused on aggregate properties of embryoid bodies or tissue-engineered constructs containing variable cell numbers and densities $[18,19]$. To the best of

Departments of ${ }^{1}$ Bioengineering, ${ }^{2}$ Institute for Stem Cell \& Regenerative Medicine, ${ }^{3}$ Department of Pathology, ${ }^{4}$ Center for Cardiovascular Biology, University of Washington, Seattle, Washington. 
our knowledge, no studies as of yet have examined the effects of prolonged in vitro culture on the contractile and structural maturation of either hESC- or hiPSC-CMs. To resolve these uncertainties, we tested the hypothesis that both hESC- and iPSC-CMs would show an enhanced structural organization and functional performance over time, and that these changes are readily apparent at the resolution of the single cell. To accomplish this, we developed a long-term culture protocol capable of supporting highly purified PSC$\mathrm{CM}$ development for over 150 days in vitro. Compared to the early-stage hESC-CMs, these late-stage hESC-CMs exhibit increased functional performance as measured by contractile, calcium-transient, and electrophysiological endpoints. hiPSCCMs subjected to the same protocol demonstrated similar levels of morphological maturation and identical improvements in contractile performance. Finally, both hESC-CMs and hiPSC-CMs displayed a remarkable upregulation in expression of the key cardiac structural genes, most notably $\beta$-myosin heavy chain, to similar levels found in the adult human heart. To our knowledge, this represents the first study to measure and demonstrate meaningful long-term enhancement in the contractile and structural properties of individual hESC-CMs and hiPSC-CMs to the levels approaching those found in adult CMs. Our results suggest that these cells may possess the capability to generate new force-producing units and perhaps prevent heart failure upon transplantation.

\section{Methods}

\section{PSC maintenance and guided cardiac differentiation}

All experiments were approved by the University of Washington Embryonic Stem Cell Research Oversight Committee (ESCRO) and conducted using the H7 (NIHhESC-10-0061) and RuES-2 (NIHhESC-09-0013) hESC lines and the iMR90 hiPSC line. The H7 and iMR90 lines were kindly provided by WiCell Research Institute (Madison, WI), and the RuES-2 line by Prof. Ali Brivanlou (Rockefeller University, New York, NY). PSCs were maintained and differentiated as previously described [5]. Briefly, PSCs were cultured in feeder-free conditions on Matrigel-coated plates (BD Biosciences) and fed with a mouse embryonic fibroblast-conditioned medium (MEF-CM) supplemented with $4 \mathrm{ng} / \mathrm{mL}$ basic fibroblast growth factor. Before cardiac differentiation, cells were passaged using versene-EDTA and replated at a density of 175,000 cells $/ \mathrm{cm}^{2}$. To induce cardiogenesis, we replaced the MEF-CM with RPMIB27 (Gibco) supplemented with L-glutamine, Matrigel, and $100 \mathrm{ng} / \mathrm{mL}$ recombinant human activin A (R\&D Systems). After $24 \mathrm{~h}$, the medium was switched to RPMI-B27 supplemented with L-glutamine and $10 \mathrm{ng} / \mathrm{mL}$ recombinant human bone morphogenetic protein-4 (BMP-4; R\&D Systems). Four days later, the medium was aspirated, and the cells were subsequently fed every 3-5 days with RPMI-B27 containing Lglutamine. Cells typically began beating spontaneously on approximately day 14 postinduction.

\section{hESC-CM maturation}

Glass coverslips (Corning) were prepared by overnight treatment with $0.1 \%$ polyethyleneimine (PEI; Sigma) at $4^{\circ} \mathrm{C}$, rinsed thoroughly with PBS, and incubated with $0.67 \%$ gelatin (Sigma) overnight at $4^{\circ} \mathrm{C}$. After 20 days of in vitro differentiation, PSC-CMs were dispersed using $0.05 \%$
trypsin-EDTA and replated at 30,000 cells $/ \mathrm{cm}^{2}$ onto the PEIgelatin glass coverslips. Cultures were fed every other day thereafter with serum-free RPMI-B27 plus L-glutamine. Only cell preparations containing $>75 \%$ cardiac troponin $\mathrm{T}+$ $(\mathrm{cTnT}+) \mathrm{CMs}$ (by flow cytometry) were used for these experiments, and any cultures exhibiting noncardiac cell overgrowth were excluded from analysis. Cultures were monitored daily for signs of contractile structure organization and the emergence of sarcomere banding.

\section{Optical contraction analysis}

Cells were visualized using a Nikon TS100 inverted microscope coupled to an Ionoptix videomicroscopy system (Ionoptix). Only isolated contracting hESC-CMs were chosen for analysis. Before measurement, cells were placed in a stimulus chamber containing HEPES-buffered Tyrode's solution and maintained at $25^{\circ} \mathrm{C}$ for the duration of the experiment unless otherwise specified. Experiments requiring administration of pharmacological agents employed a rapid solution stepper setup with temperature control to keep the perfusates at $37^{\circ} \mathrm{C}$. Traces were collected and analyzed using Ionwizard software, and a minimum of five traces were analyzed and averaged for each cell.

\section{Electrophysiology}

Electrophysiological endpoints were acquired as previously reported in detail [20]. All experiments were conducted using a HEKA EPC-10 patch-clamp amplifier (HEKA Instruments) in a current clamp mode. We recorded from isolated spontaneously beating hESC-CMs using pipettes with resistance of $2-4 \mathrm{M} \Omega$ by establishing a gigaohm seal and recording using the traditional ruptured patch approach. All recordings were performed at $37^{\circ} \mathrm{C}$, and all data were analyzed using Patchmaster and IgorPro software.

\section{Calcium imaging}

Intracellular calcium content was measured using the ratiometric indicator dye fura2-AM as described previously [21]. In brief, cells were incubated in $1 \mu \mathrm{M}$ fura2-AM dye for $20 \mathrm{~min}$ at $37^{\circ} \mathrm{C}$ and washed with PBS. Spontaneous $\mathrm{Ca}^{2+}$ transients were then monitored with the Ionoptix Stepper Switch system coupled to a Nikon inverted fluorescence microscope. The fluorescence signal was acquired using a $40 \times$ Olympus objective and passed through a 510-nm filter, and the signal was quantified using a photomultiplier tube.

\section{Immunocytochemistry}

Cells were fixed in $4 \%$ paraformaldehyde for $10 \mathrm{~min}$ and permeabilized using $0.25 \%$ Triton $X-100$ for $6 \mathrm{~min}$. The fixed cells were blocked with $1.5 \%$ normal goat serum for $1 \mathrm{~h}$ at room temperature and incubated overnight at $4^{\circ} \mathrm{C}$ with a primary antibody at 1:500. Antibodies used in this study include mouse anti- $\alpha$-actinin (Sigma), mouse anti-cTnT (Abcam), rabbit anti-Cx43 (Thermo), rabbit anti-smooth muscle actin (Abcam), and mouse anti-cytokeratin (Dako). Samples receiving actin staining were incubated with 1:50 FITC-labeled phalloidin (Sigma) for $5 \mathrm{~min}$ at RT. The samples were rinsed with PBS and incubated with a secondary antibody (Alexa Fluor 488 or 594) at 1:500 for $1 \mathrm{~h}$ at RT, 
rinsed, and coverslipped using Vectashield containing DAPI (Vector Labs).

\section{Imaging and morphological analysis}

Bright-field and fluorescent images were acquired using a Zeiss AxioCam mounted to a Zeiss AxioObserver microscope, and confocal images were acquired using a Nikon A1R confocal microscope. Images were processed and exported using Adobe Photoshop; the images were quantified in ImageJ software, using standard analysis plugins. Each cell was analyzed for average sarcomere length, cell area, cell perimeter, and cell circularity index.

\section{Flow cytometry}

Cells were fixed in $4 \%$ paraformaldehyde for $10 \mathrm{~min}$ and incubated with 1:100 anti-cTnT or isotype control mouse IgG (eBioscience) in $0.75 \%$ saponin followed by visualization with goat anti-mouse conjugated to phycoerythrin. Samples were run on a BD Sciences FACS Canto flow cytometer and were analyzed using FlowJo software.

\section{Quantitative PCR}

Total RNA was isolated using the Qiagen RNeasy kit, and mRNA was reverse transcribed using the Superscript III firststrand cDNA synthesis kit (Invitrogen). All primers were purchased from Real Time Primers, and qPCR was performed using SYBR green chemistry and an ABI 7900HT instrument. Samples were normalized using GAPDH as a housekeeping gene.

\section{Transmission electron microscopy}

Cells were fixed overnight in $1 / 2$ strength Karnovsky's ( $2 \%$ paraformaldehyde $/ 2.5 \%$ glutaraldehyde buffered with $0.2 \mathrm{M}$ cacodylate) and postfixed in $2 \% \mathrm{OsO}_{4}$ buffered in $0.2 \mathrm{M}$ cacodylate buffer. After dehydration, cells were embedded in Epon 812 (Electron Microscopy Sciences), thin sectioned $(70 \mathrm{~nm})$, and stained with uranyl acetate for $2 \mathrm{~h}$ and lead citrate for $5 \mathrm{~min}$. The samples were imaged using a JEOL 1230 transmission electron microscope set to $80 \mathrm{kV}$, and the images were captured using a Gatan digital imaging system.

\section{Statistical analysis}

All data are presented as mean \pm S.E.M. All data were compiled in Microsoft Excel, and normal parameter distributions were confirmed using the Shapiro-Wilk test for normality. All statistical tests were performed using a twotailed Student's $t$-test with unequal sample variance or Fisher's exact test for proportions.

\section{Results \\ hESC-CMs can be differentiated with high purity and grown in long-term culture}

hESCs were maintained and differentiated as previously described (Fig. 1A) [5]. Approximately 14 days after induction, cultures began displaying a contractile phenotype, and flow cytometry analysis of representative cultures at the time of replating on day 20 indicated a CM purity of $86.6 \% \pm 6.14 \%$ as measured by $\mathrm{cTnT}+$ staining (Fig. 1B). At this point, the cells were enzymatically dispersed and replated at a low density onto coverslips coated with PEI and gelatin and maintained for up to 6 months. This PEI/gelatin substrate appeared to improve the $\mathrm{CM}$ purity by favoring their initial adhesion at the day-20 replating step, and $99.6 \% \pm 0.1 \%$ of cells exhibited cTnT + immunostaining by the late-stage time point (Supplementary Fig. S1C; Supplementary Data are available online at www.liebertpub.com/scd); $10.1 \% \pm 1 \%$ of cells also costained for smooth muscle $\alpha$-actin in either fibril or sarcomere staining patterns (Supplementary Fig. S1A, B). We also stained for cytokeratins, an epithelial marker. Interestingly, while we found only exceedingly rare cytokeratin+ cells, the latter also coexpressed cTnT in the typical striated sarcomere pattern (Supplementary Fig. S1D-F).

\section{hESC-CMs slowly grow in size and contractile apparatus organization}

After replating, cultures were examined at regular intervals for changes in the morphology. hESC-CMs and hiPSC-CMs between 20 and 40 days postinduction were categorized as early stage. Typically exhibiting spontaneous contractile activity, early-stage myocytes appeared as small, rounded cells lacking any discernible organized cardiac structure when viewed by phase-contrast microscopy (Fig. 2A). Immunocytochemical staining for $\alpha$-actinin, a cardiac Z-disk protein, revealed poorly organized contractile machinery, characterized by low myofibril density and orientation and variable Z-disc alignment (Fig. 2B). Over the course of the next 2 months, PSC-CMs slowly altered their appearance by becoming larger, more elongated, and less circular. Between days 80 and 100, cells began exhibiting signs of contractile machinery organization along their entire length under phase-contrast microscopy. These cells demonstrated repetitive banding patterns characteristic of organized sarcomeres with good registration across the entire width of the cell. hESC-CMs and hiPSC-CMs between days 80 and 120 of in vitro development were termed late-stage cells (Fig. 2C-F). Quantitative immunocytochemical analysis of late-stage hESC-CMs demonstrated dramatic maturation in their morphology and immunophenotype (Fig. 3A). The percentage of multinucleated CMs, which ranges from $25 \%$ to $57 \%$ in adult myocardium [22,23], increased from $4.2 \%$ in early-stage hESC-CMs to $35.3 \%$ in late-stage hESC-CMs (Fig. 3B) $(P<0.001)$. Compared to their early-stage counterparts, latestage hESC-CMs showed an increased cell area $\left(480 \pm 32 \mu \mathrm{m}^{2}\right.$ vs. $\left.1716 \pm 150 \mu \mathrm{m}^{2}, P<0.001\right)$ and perimeter $(131 \pm 32 \mu \mathrm{m}$ vs. $284 \pm 15 \mu \mathrm{m}, P<0.001)$, as well as a decrease in the circularity index $(0.38 \pm 0.02$ vs. $0.28 \pm 0.02, P<0.01)$ (Fig. 3D-F). In addition, late-stage hESC-CMs demonstrated dramatic increases in the density and alignment of myofibrils throughout the cytoplasm of the cell. Importantly, these cells had a far greater number of aligned myofibrils in register, as evidenced by an increase in the width of continuous Z-bands in both bright-field and confocal microscopy. Finally, the resting sarcomere length (measured by the distance between Z-disks) increased from $1.65 \pm 0.02 \mu \mathrm{m}$ in early-stage hESC-CMs to $1.81 \pm 0.01 \mu \mathrm{m}(P<0.001)$ in late-stage hESC-CMs (Fig. 3C). Despite these dramatic phenotypic changes, however, we failed to identify any 


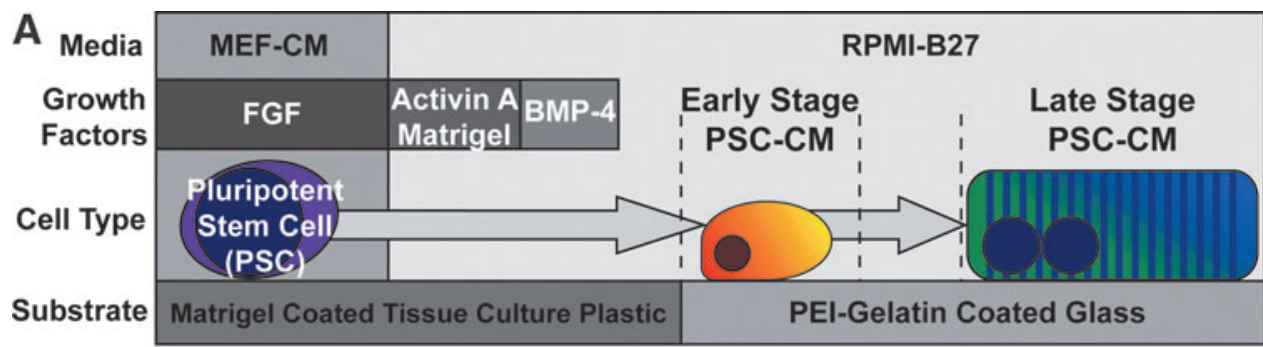

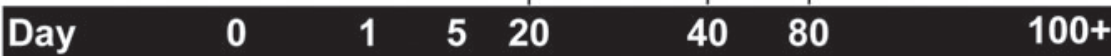
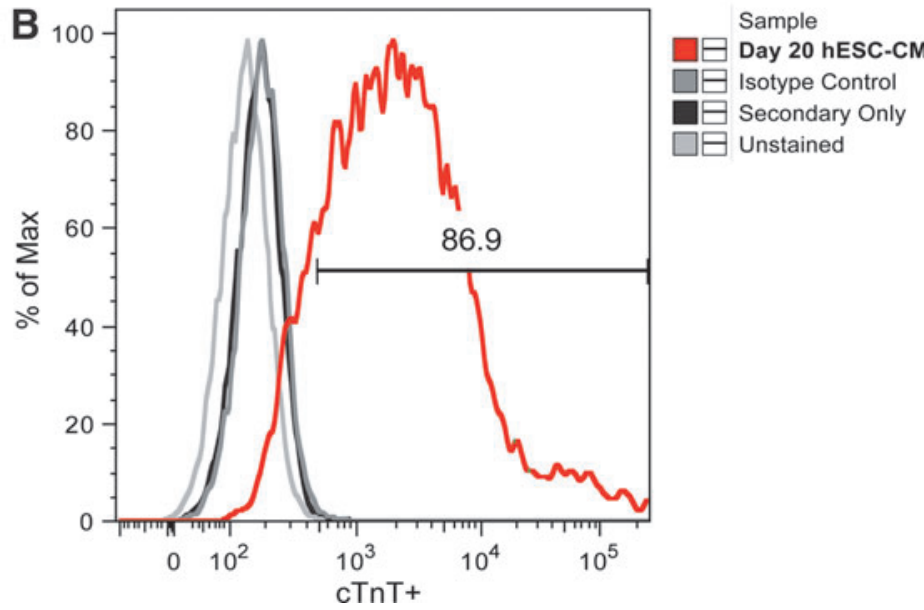

FIG. 1. Differentiation and maturation scheme for early- and late-stage cardiomyocytes (CMs) from pluripotent stem cells. (A) hESCs and iPSCs were maintained in a mouse embryonic fibroblast-conditioned medium (MEF-CM) supplemented with fibroblast growth factor (FGF) and differentiated into CMs by serial treatment with activin A and BMP-4. Spontaneous beating activity typically commenced by day 14 . On day 20, PSC-CMs were replated onto glass coverslips coated with PEI-gelatin and then maintained for up to 6 months in culture. We classified cells between days 20 and 40 as early-stage PSC-CMs and cells between days 80 and 120 as late-stage PSC-CMs. (B) Representative flow cytometry analysis of hESC-CMs at day 20 demonstrated $86.9 \%$ cardiac purity. BMP-4, bone morphogenetic protein-4; cTnT+, cardiac troponin T+; hESC, human embryonic stem cell; PEI, polyethyleneimine; PSC-CMs, pluripotent stem cell-derived cardiomyocytes. Color images available online at www.liebertpub.com/scd

clear t-tubule formation by Di-8-ANEPPS or wheat germ agglutinin membrane staining (data not shown). We did, however, see robust expression in late-stage cells of the gap-junction protein connexin-43, which localized to the perinuclear region and to the periphery of the cell (Supplementary Fig. S2).

\section{Ultrastructural analysis shows increased myofibrillar density and organization in late-stage hESC-CMs}

The ultrastructural elements underlying these morphological changes were analyzed by transmission electron microscopy. Images obtained from early-stage hESC-CMs
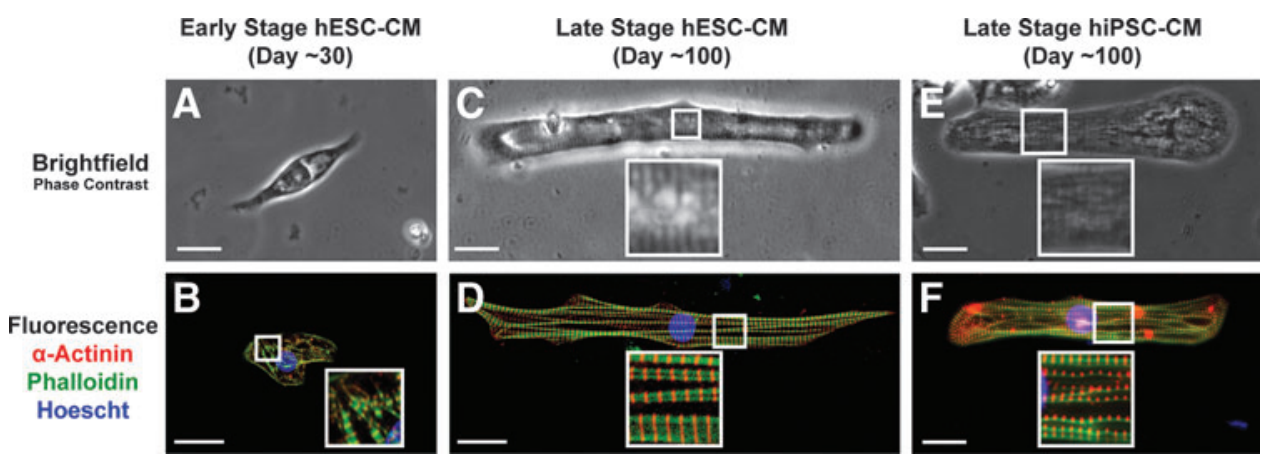

FIG. 2. Long-term culture induces significant changes in hESC-CM and iPSC-CM morphology. (A) By phase-contrast microscopy, early-stage hESC-CMs were round and lacked any discernable sarcomeric elements. (B) Cells at this stage were fixed and stained for $\alpha$-actinin + phalloidin and showed an irregular subcellular organization and low myofibril density. (C) In contrast, late-stage hESC-CMs demonstrated sarcomeres clearly visible by phase-contrast microscopy and (D) a high degree of myofibril density, alignment, and z-disk registration. (E) Late-stage iPSC-CMs demonstrated similar enhancements by phasecontrast imaging and (F) immunocytochemistry. Scale bar $25 \mu \mathrm{m}$. Color images available online at www.liebertpub.com/scd 


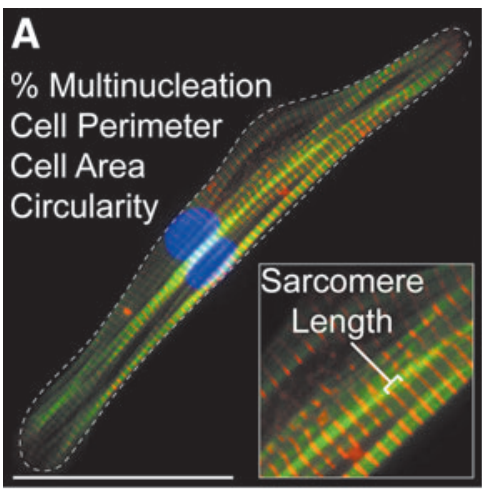

D

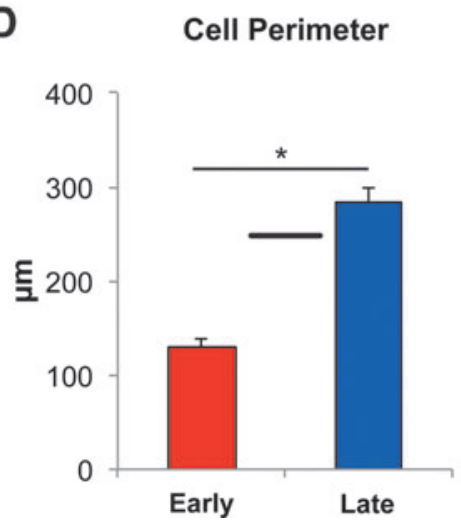

B

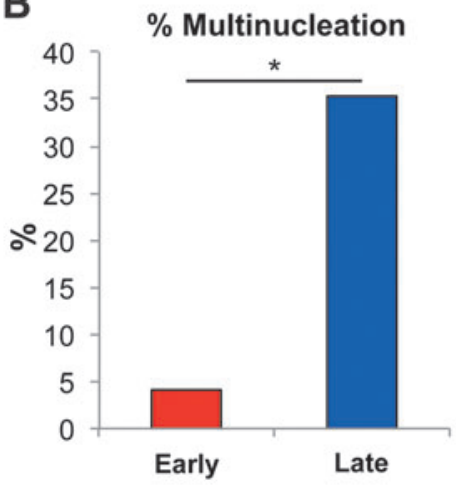

$E$

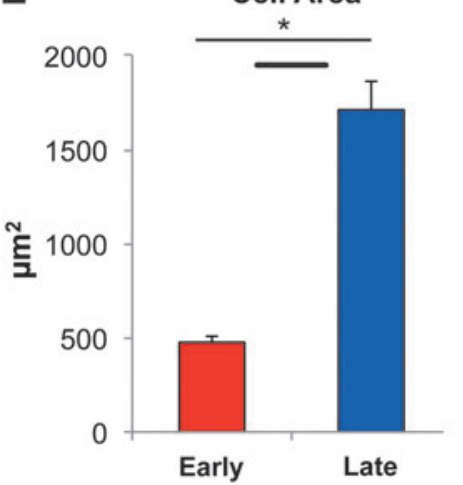

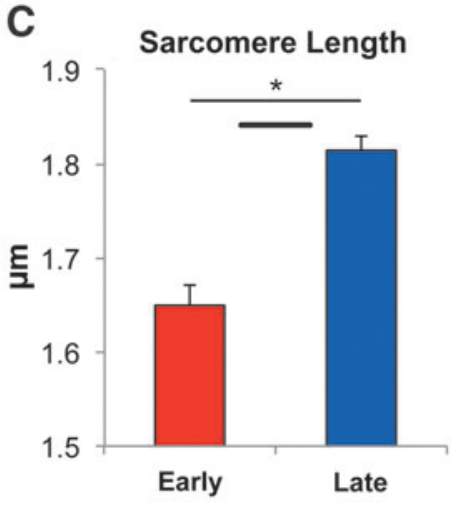

$\mathbf{F}$

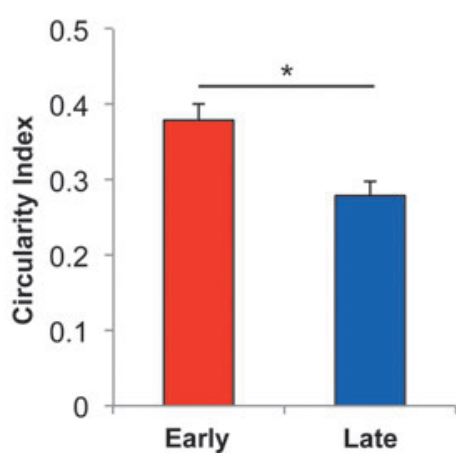

FIG. 3. Late-stage hESC-CMs recapitulate many features of adult human CM morphology. (A) Fixed and stained cells were imaged using fluorescence microscopy and quantitatively analyzed. Scale bar $50 \mu \mathrm{m}$. (B) Compared to early-stage hESC-CMs, late-stage hESC-CMs demonstrated significant changes in a multinucleated cell fraction, (C) sarcomere length (D), cell perimeter, (E) cell area, and (F) circularity index. These numbers compare favorably with the previously reported values for these parameters in adult human ventricular cardiomyocytes [27], indicated graphically by the solid black reference lines. $n=24-34$ per condition. ${ }^{*} P<0.05$ versus early-stage hESC-CMs. Color images available online at www.liebertpub.com/scd

suggest a highly underdeveloped contractile machinery composed of misaligned myofibrils at low density (Fig. 4A). Higher magnification of these myofibril bundles demonstrated punctate electron-dense aggregates previously described as Z-bodies [24,25] rather than the moremature, linear Z-disks found in adult CMs (Fig. 4B). Spanning between these structures were thick filaments composed of myosin at a relatively low density. In contrast, late-stage hESC-CMs showed significant improvements in myofibril alignment, density, and morphology (Fig. 4C). Highly aligned myofibrils ran parallel to the long axis of the cell and were interspersed with larger quantities of mitochondria. Investigation of single sarcomeres in late-stage cells (Fig. 4D) showed an adultlike appearance of Z-disks in register, A- and I-bands, and $\mathrm{H}$-zones, but no clear M-band. Ultrastructural studies revealed additional evidence of greater structural maturation in the late-stage myocytes, including intercalated disc structures (Fig. S3A-B) and mitochondria with prominent cristae located adjacent to myofibril bundles (Supplementary Fig. S3C). On the other hand, we found no clear examples of t-tubule formation at the ultrastructural level, though the cells did show scalloping of the sarcolemma in register with the Z-disks (Supplementary Fig. S3D).

\section{PSC-CM contractile performance improves during long-term culture}

We next used optical video microscopy to track developmental changes in the contractile properties of hESC-CMs and hiPSC-CMs (Fig. 5). Early-stage PSC-CMs lack visible sarcomeres, so we quantified contractile performance by monitoring changes in the cell length. Similar cell length measurements were also made in late-stage hESC-CMs (Supplementary Fig. S4), but a better measure of contractile performance is to monitor sarcomere length changes during contraction, which has been shown previously to correlate well with whole-cell contractility [26]. The magnitude of contraction for early-stage hESC-CMs and hiPSC-CMs was $5.74 \% \pm 0.51 \%$ and $4.95 \% \pm 0.68 \%$ (respectively) of resting length, and this increased to $10.50 \% \pm 0.87 \%(P<0.0001)$ and $10.17 \% \pm 1.35 \%(P<0.01)$ of the resting sarcomere length for late-stage cells (Fig. 5B). Additionally, late-stage hESC-CMs and hiPSC-CMs exhibited slightly slower contractile kinetics, including time to $50 \%$ peak contraction $(P<0.05)$ and time to peak contraction $(P<0.05)$ (Fig. $5 C)$. There was no difference in the rate of spontaneous contraction between early- and late-stage hESC-CMs. To confirm these results in an independent hESC population, we also performed contractility analysis experiments in a second line of hESC-CMs, the 
FIG. 4. Late-stage hESC-CMs demonstrate dramatically increased ultrastructural organization. (A) Transmission electron microscopy images of earlystage hESC-CMs at low magnification show fragmented myofibrils at low density (outlined by the white dashed line). (B) Higher-magnification images reveal fragmented Z-disks called Zbodies (ZB) and irregularly spaced thick filaments (TF). (C) In contrast, late-stage hESC-CMs at a low magnification show a high density of organized and aligned myofibrils. (D) Sarcomeres under high magnification show clear aligned Z-disks (Z) and organized A- and I-bands with a clear H-zone $(\mathrm{H})$.

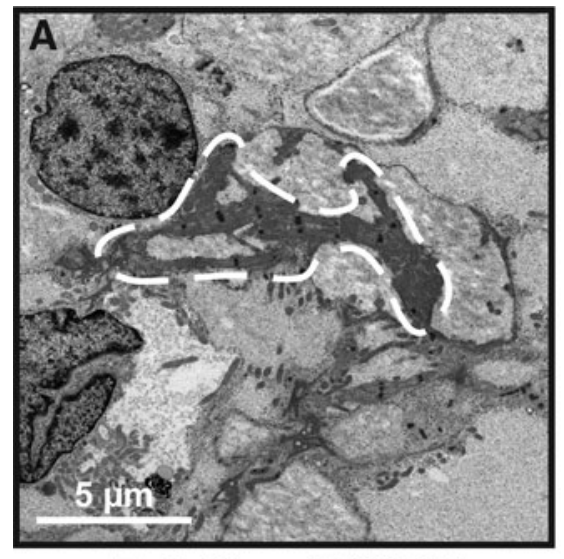

Early Stage hESC-CM

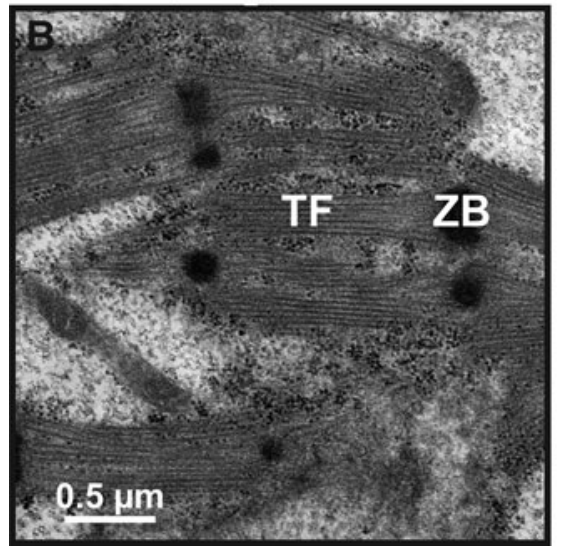

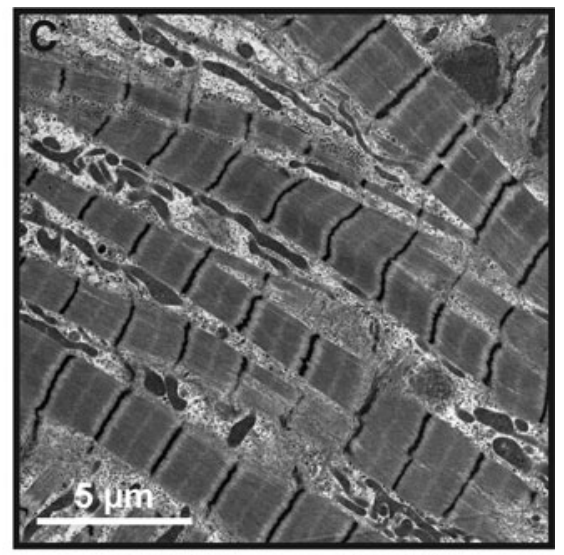

Late Stage hESC-CM

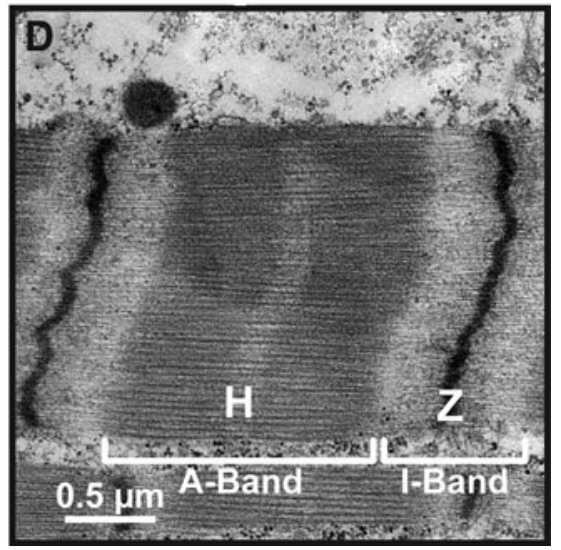

RuES-2 line, and saw nearly identical performance increases in late-stage contractility (Supplementary Fig. S5).

\section{Late-stage hESC-CMs demonstrate faster $\mathrm{Ca}^{2+}$-transient kinetics}

To further investigate the mechanism underlying changes in the kinetics of contractility over time, we compared the $\left[\mathrm{Ca}^{2+}\right]_{i}$ transient characteristics of early- versus late-stage hESC-CMs (Fig. 6) using the ratiometric dye fura-2. While the peak transient amplitude remained unchanged in earlyversus late-stage cells $\left(0.22 \pm 0.02\right.$ vs. $\left.0.24 \pm 0.02 \mathrm{~F} / \mathrm{F}_{0}, P=0.47\right)$ (Fig. 6B), the maximal upstroke and decay velocities were significantly higher in late-stage hESC-CMs (Fig. 6C, D), and the time to peak $\left[\mathrm{Ca}^{2+}\right]_{\mathrm{i}}$ was significantly shorter $(342 \pm 2 \mathrm{~ms}$ vs. $102 \pm 1 \mathrm{~ms}, P<0.0001)$ for late-stage cells (Fig. $6 \mathrm{E}$ ). The kinetics of $\mathrm{Ca}^{2+}$ reuptake also changed over time in culture, with late-stage hESC-CMs demonstrating a faster $\mathrm{Ca}^{2+}$ transient decay (Fig. 6F) as measured by the time to $50 \%$ relaxation $(446 \pm 3 \mathrm{~ms}$ vs. $227 \pm 2 \mathrm{~ms}, P<0.001)$ (Fig. $6 \mathrm{~F}$ ).
A

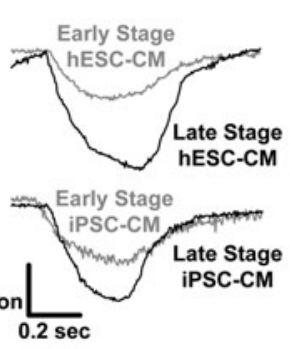

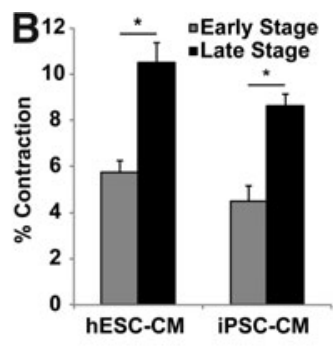

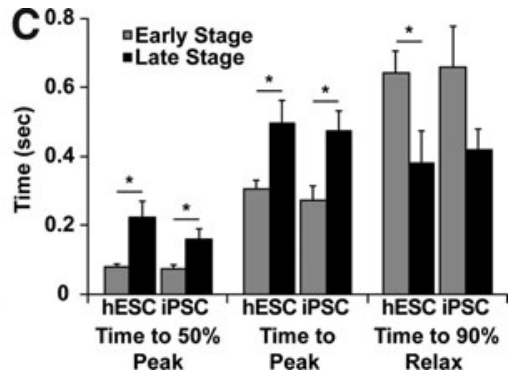

FIG. 5. Late-stage hESC-CMs and iPSC-CMs demonstrate increased contractile performance with slowed kinetics. (A) Spontaneous contractions of early- and late-stage cells were obtained using optical videomicroscopy. (B) Quantitative analysis revealed that early-stage hESC-CMs and iPSC-CMs contract $\sim 5 \%$ of their resting length, while the late-stage hESC$\mathrm{CMs}$ and iPSC-CMs exhibit contractions roughly twice as large in magnitude. (C) In addition to increased contractile magnitude, late-stage hESC-CMs and iPSC-CMs also contracted with slowed kinetics compared to their early-stage counterparts. Direct comparison between iPSC-CMs and hESC-CMs at early stage or late stage showed no statistical differences in any parameter. $n=9-31$ per condition ${ }^{*} P<0.05$. 

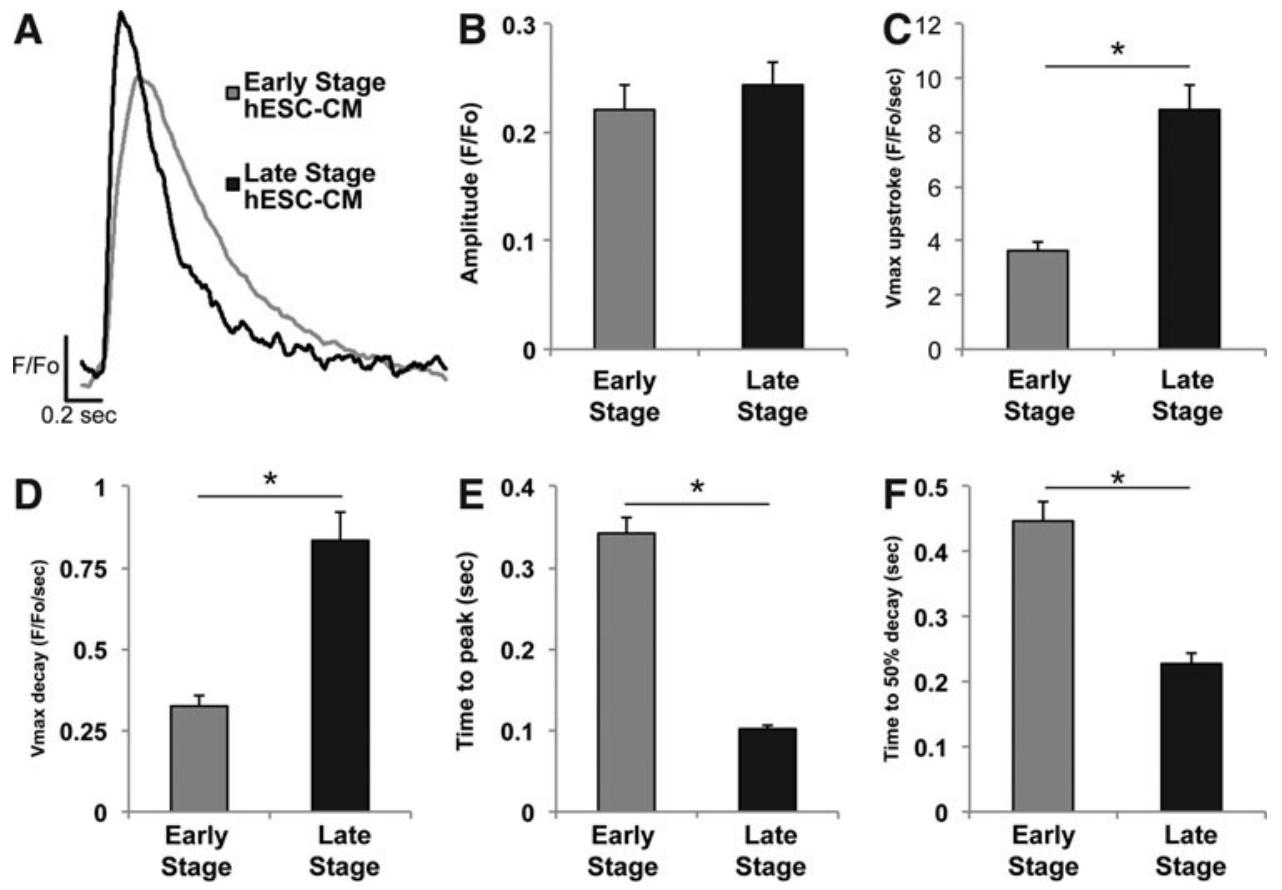

FIG. 6. Late-stage hESCCMs exhibit increased calcium-transient kinetics, but no change in magnitude. Calcium transients were assessed in hESC-CMs loaded with the ratiometric indicator fura-2. (A) Representative fluorescence transients from earlyand late-stage hESC-CMs. (B) Although transient amplitude magnitudes were similar, the kinetics were significantly different in latestage cells, as indicated by increases in maximal transient (C) upstroke and (D) decay velocities, reduced (E) time to peak $\left[\mathrm{Ca}^{2+}\right]_{i}$, and $(\mathbf{F})$ reduced time to $50 \%$ decay. $n=6-7$ per condition ${ }^{*} P<0.05$ versus early-stage hESC-CMs.

\section{Late-stage hESC-CMs exhibit mature action potential characteristics}

To assess whether the changes in the structure and contractile function were accompanied by changes in action potential properties, we obtained current clamp recordings of early- versus late-stage hESC-CMs (Fig. 7). These studies demonstrated a dramatic increase in the maximal upstroke velocity ( $\mathrm{dV} / \mathrm{dt} \max )$ from $44 \pm 10.8 \mathrm{~V} / \mathrm{s}$ in early-stage hESCCMs to $188.7 \pm 12.6 \mathrm{~V} / \mathrm{s}$ in late-stage hESC-CMs $(P<0.05)$ (Fig. 7C). Further, when compared to early-stage cells, latestage cells had a more hyperpolarized maximum diastolic

potential (MDPs, $-57.3 \pm 1.9 \mathrm{mV}$ vs. $-68.2 \pm 2.1 \mathrm{mV}$, respectively, $P<0.05)$ and larger action potential amplitude $(94.1 \pm 3.4 \mathrm{mV}$ vs. $113.2 \pm 2.8 \mathrm{mV}$, respectively, $P<0.05)$ (Fig. $7 C)$. There were no significant differences noted in action potential duration (measured at $50 \%$ and $90 \%$ of repolarization).

\section{Late-stage hESC-CMs retain adrenergic responsiveness}

Previous reports have demonstrated that early-stage hESC-CMs respond to adrenergic stimulation $[27,28]$.

A

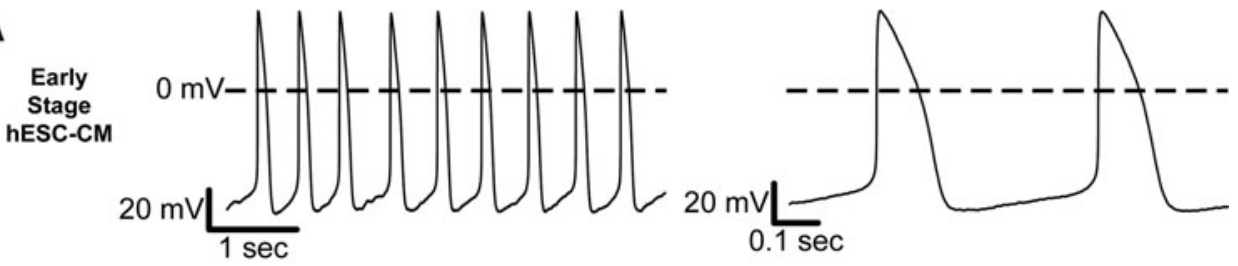

B
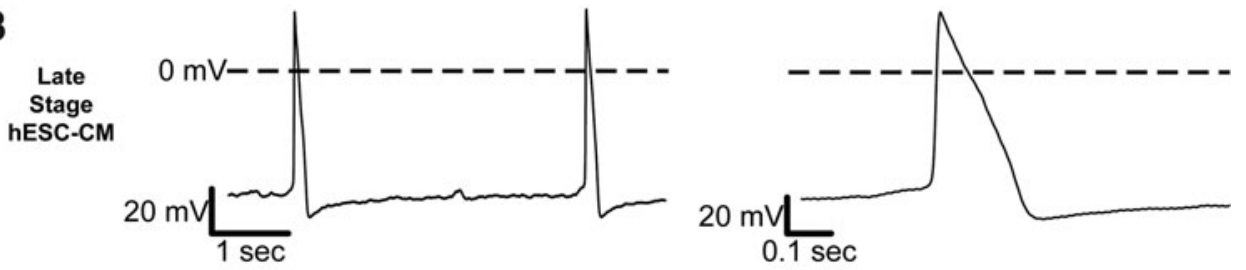

C
\begin{tabular}{|c|c|c|c|c|c|c|}
\multicolumn{1}{c}{$\begin{array}{c}\mathrm{dV} / \mathrm{dt} \text { max } \\
(\mathrm{V} / \mathrm{s})\end{array}$} & $\begin{array}{c}\text { APA } \\
(\mathrm{mV})\end{array}$ & $\begin{array}{c}\text { MDP } \\
(\mathrm{mV})\end{array}$ & $\begin{array}{c}\text { APD50 } \\
(\mathrm{ms})\end{array}$ & $\begin{array}{c}\text { APD90 } \\
(\mathrm{ms})\end{array}$ & $\begin{array}{c}\text { Rate } \\
(\mathrm{bpm})\end{array}$ \\
\hline Early Stage hESC-CM & $44.0 \pm 10.8$ & $94.1 \pm 3.4$ & $-57.3 \pm 1.9$ & $88.3 \pm 5.0$ & $146.4 \pm 10.5$ & $102.2 \pm 11.8$ \\
\hline Late Stage hESC-CM & $188.7 \pm 12.6^{*}$ & $113.2 \pm 2.8^{*}$ & $-68.2 \pm 2.1^{*}$ & $87.0 \pm 9.7$ & $188.9 \pm 35.8$ & $9.3 \pm 3.1^{*}$ \\
\hline
\end{tabular}

FIG. 7. Late-stage hESCCMs show significantly enhanced action potential upstroke and a hyperpolarized maximum diastolic potential (MDP). (A) Representative recording of early-stage $h E S C$ $\mathrm{CM}$ action potentials demonstrates a relatively high spontaneous beat rate. (B) Compared to early-stage cells, late-stage hESC-CMs demonstrated a slower rate and higher maximum upstroke velocity (dV/dt). (C) Compared to their early-stage counterparts, late-stage hESCCMs showed a hyperpolarized MDP and larger action potential amplitude (APA). There was no statistical change in either the action potential duration to $50 \%$ or $90 \%$ of repolarization (APD50 or APD90, respectively). $n=$ 5-11 per condition ${ }^{*} P<0.05$. 
FIG. 8. Late-stage hESC-CMs and iPSC$\mathrm{CMs}$ robustly upregulate the key cardiac structural and functional genes. Gene expression levels for the key cardiac genes were measured via $\mathrm{QPCR}$ and normalized to values obtained for early-stage hESC-CMs. Late-stage hESC-CMs and iPSC-CMs (dark gray bars) demonstrated increased expression of MYH7 ( $\beta$-myosin heavy chain), MYH6 ( $\alpha$ myosin heavy chain), GJA1 (connexin-43), HCN4 (hyperpolarization-activated $\mathrm{K}^{+}$ channel), and SERCA (sarcoendoplasmic reticulum ATPase). The majority of these transcript levels match reasonably well to the values observed in a healthy adult human myocardium. $n=3$ per condition ${ }^{*} P<0.05$ versus corresponding early-stage PSC-CMs. ${ }^{\dagger} P<0.05$ versus adult human heart. Color images available online at www.liebertpub.com/scd

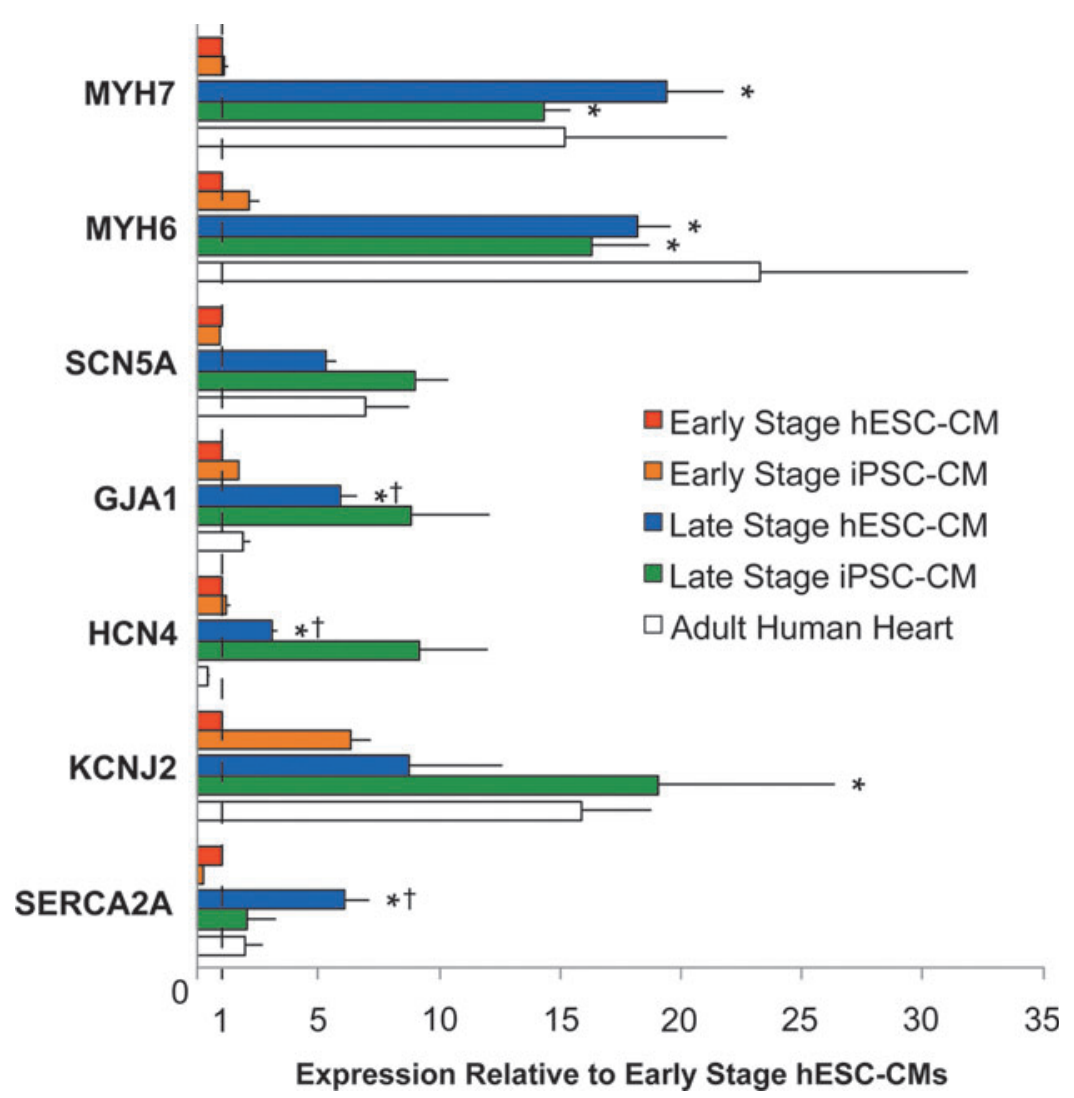

in late-stage hESC-CMs and hiPSC-CMs, respectively $(P<0.05)$. We also found significant increases in other genes, including connexin-43 (GJA1), HCN4 (If channel), and the sarcoendoplasmic reticulum ATPase $(S E R C A 2 A)(P<0.05)$. Conversely, the expression of the fast $\mathrm{Na}^{+}$ion channel $(S C N 5 A)$ and the $\mathrm{K}^{+}$inward rectifier (KCNJ2) showed no difference in expression between early and late stages in either population.

\section{Discussion}

The production of large quantities of PSC-CMs offers an attractive option for regenerating bona fide human myocardium lost during myocardial infarction. However, for this strategy to provide a maximal therapeutic benefit, the graft cells must recapitulate the structure and contractile performance of adult ventricular CMs. Before this challenge can be fully addressed, it is important to assess the baseline timecourse and maturation potential of PSC-CMs in vitro. We reasoned that prolonged duration in culture may be required to approach the maturation normally achieved by the human heart, which develops over a gestational period of $\sim 40$ weeks and continues to mature for several years after birth [1]. To test this hypothesis, we developed a cell culture protocol capable of generating and maintaining highly purified hESC- and hiPSC-CMs for several months in vitro. Our analysis was restricted to two time points, both to facilitate the examination of comprehensive structural and functional endpoints, and because all preclinical transplantation work as of yet has employed cell preparations comparable to the early-stage hESC-CMs and hiPSC-CMs (day 20-40) in this 
study [5,29-32]. While the late-stage cultures described here showed dramatically altered phenotypic properties, it would also be of interest to examine even later timepoints in future work. This, however, would be challenging in terms of experimental throughput.

In agreement with previously published reports $[9,10,33]$, early-stage hESC-CMs demonstrated poor subcellular organization and structural alignment, weak contractile performance, and relatively slow calcium release and reuptake kinetics. Over the subsequent weeks, however, these cells grew in size and elongated in shape. Sarcomeres aligned along the long axis of the cell, and Z-disks became regular and in register with neighboring myofibrils. After 3-4 months in culture, essentially all CMs exhibited an organized sarcomeric structure, and approximately one-third were multinucleated. Interestingly, these late-stage CMs showed many morphological parameters (eg, cell length, cell area, and sarcomere length) approaching the values previously reported for adult human CMs in culture [22,34]. Ultrastructural analysis confirmed the preceding findings made at the light microscopic level and revealed a highly ordered contractile apparatus with signs of mature CM structures, including dense myofibrils with clear A- and I-bands, fascia adherens, and gap junctions. These cells can be stably cultured for at least 6 months, and they survive passaging (although with a transient loss of structural organization). To our knowledge, no one has previously described hESC-CMs or hiPSC-CMs with such a dramatic degree of structural maturation, even when exogenous promaturation stimuli (eg, electromechanical conditioning) have been applied $[11,35]$.

In addition to examining the morphology and ultrastructure, we investigated the functional performance of latestage hESC-CMs and hiPSC-CMs and saw a robust increase in spontaneous contraction magnitude (Fig. 5). Interestingly, this increase in magnitude was accompanied by a slowing of contraction kinetics, a finding compatible with a switch in relative expression from the faster $\alpha$-isoform to the slower $\beta$-isoform of myosin heavy chain. This hypothesis was supported by the robust induction of the gene encoding for $\beta$-MHC (MYH7) over early-stage hESC-CMs. This finding could also be explained by a shift down the force-velocity curve, as these late-stage cells are more adherent and must contract against a greater perceived load than the comparatively unrestrained early-stage cells. One limitation of the current study is the lack of true force production metrics, which could provide evidence for the latter possibility. Future studies would benefit from the development of a reliable method to accomplish force measurements that is compatible with the long-term culture of PSC-CMs on rigid substrates.

The changes in cell contractility were also accompanied by changes in $\mathrm{Ca}^{2+}$-handling properties. We found an increase in the kinetics of $\mathrm{Ca}^{2+}$ release and sequestration, but no change in the transient magnitude, suggesting a modest improvement in the calcium-handling capabilities of latestage cells. In prior work, our group has shown that the hESC-CM populations equivalent to the early-stage cells in this study have surprisingly mature mechanisms of excitation-contraction coupling and $\mathrm{Ca}^{2+}$ handling [36]. While we have shown that early-stage cells do have intact SR $\mathrm{Ca}^{2+}$ cycling, the present finding of enhanced $\left[\mathrm{Ca}^{2+}\right]_{\mathrm{i}}$-transient kinetics in late-stage CMs proves that there is still room for functional maturation in SR $\mathrm{Ca}^{2+}$ reuptake [36]. However, neither electron microscopy nor membrane staining using wheat germ agglutinin or Di-8-ANNEPPS demonstrated definitive t-tubules in any developmental stage of hESCCMs, which is consistent with previous reports [37,38].

In agreement with previously published work [15], latestage hESC-CMs in the present study showed significant changes to key electrophysiological parameters. The increased MDP may reflect the increased expression of KCNJ2, which underlies the $\mathrm{I}_{\mathrm{K} 1}$ current responsible for hyperpolarization. Prior work by Satin et al. suggests that even earlystage hESC-CMs have abundant voltage-dependent fast sodium current $\mathrm{I}_{\mathrm{Na}}$ [39]. Given this and our finding of no significant change in SCNA5 expression, we speculate that the enhanced action potential upstroke in late-stage CMs may result from the hyperpolarized MDP and a greater quantity of available $\mathrm{Na}^{+}$channels, rather than a direct increase in sodium channel content. Despite expectations to the contrary, late-stage cultures showed an increase in the expression of the HCN4, which underlies the $\mathrm{I}_{\mathrm{f}}$ current of pacemaker cell types. It is still unclear, however, whether the increase $\mathrm{HCN} 4$ is present in all CMs or is restricted to a subset of the population.

While our late-stage hESC-CMs exhibited a degree of structural and functional maturation exceeding the levels previously reported, the exact identity of the mechanistic signals driving this maturation remains unknown. A previous study implicated undefined cues derived from contaminating noncardiac cells in hESC-CM cultures, but these authors focused primarily on the maturation of electrophysiological parameters [16]. In contrast, we used highly enriched populations of CMs cultured in a basal serum-free medium, indicating that PSC-CMs are capable of a substantial degree of structural and functional maturation in the absence of exogenous promaturation signals or significant numbers of noncardiac cells. This apparent discrepancy may reflect other differences in culture conditions between the latter study and our own (eg, serum-free versus serumcontaining media) or the nature of the maturation endpoints examined.

A second candidate factor potentially driving PSC-CM maturation is the culture substrate itself. We were intrigued to observe such dramatic changes in cell shape and circularity index, given that the substrate chosen for these studies (PEI-gelatin-coated glass) contained no anisotropic or directional cues. While others have previously demonstrated the ability of immature CMs to align in response to patterned substrates [40-42] or nanotopographical cues $[43,44]$, our data prove that immature CMs possess the ability to self-organize and polarize in the absence of extrinsic directional cues. Again, the mechanisms underlying this phenomenon remain unidentified, but we speculate that a mechanical mismatch between a cell and a substrate [45] and/or local changes in the extracellular matrix [46-48] may act as potential driving factors for myofibrillogenesis. Indeed, a number of reports have demonstrated the importance of substrate stiffness on CM function and myofibrillogenesis. Kita-Matsuo et al. demonstrated that immature CMs, including hESC-CMs, respond favorably to softer physiological $(\mathrm{kPa})$ substrates, while stiffer substrates (eg, glass) caused the formation of stress fibers and 
inhibited myofibril formation $[46,48]$. Recent work by Rodriguez et al., however, showed that neonatal rat CMs exert greater twitch power when cultured on microposts of increased stiffness [49]. Moreover, Hazeltine et al. found that, when cultured on flexible substrates, early-stage hESC-CM contractility increased as the substrate stiffness increased [50]. The latter two reports correlate well with our findings in the present study, in which we observed an unprecedented degree of structural organization by hESC-CMs and hiPSCCMs cultured on nondeformable glass coverslips with $\mathrm{gPa}$ range stiffness. Hence, while the kinetics of myofibrillogenesis may be accelerated by the use of substrates of physiological stiffness, long-term culture on nonphysiological, stiffer substrates clearly also supports morphological maturation, perhaps eventually to an even greater degree. Interestingly, the observations from developmental biology suggest that myofibrillogenesis is a dynamic process that begins with the formation of premyofibrils, which form at the periphery of cells at procostameres and resemble actin stress fibers in morphology and composition [51]. We speculate that while stiff substrates may initially result in the formation of stress fibers, long-term culture may allow these structures to convert to mature myofibrils to a greater degree. We have attempted to directly test this hypothesis, but so far have not been successful in culturing hESC-CMs on flexible substrates for long periods of time ( $>2$ weeks), due to cell death and hESC-CM migration off of the flexible substrate. Hence, while driving structural maturation with culture on infinitely stiff substrates may be less physiological, this condition may still be exploitable as a practical approach for enhancing the structural and mechanical maturation of PSC-CMs.

In summary, we have developed a stable platform to study the morphological and functional changes in PSCCMs, and we have shown that hESC-CMs and hiPSC-CMs are capable of maturing to a phenotype that more closely resembles adult $\mathrm{CMs}$ in both structure and function. The remarkable similarity in contractile performance maturation parameters between two independent hESC lines and one hiPSC line suggests that this is phenomenon is robust and cell line-independent. This study provides proof-of-concept and useful baseline data for future work aimed at elucidating the mechanisms underlying these morphological changes, and we have described a platform that should serve as a useful tool for evaluating the effects of candidate hypertrophic or pharmacologic treatments. Finally, the results of this study provide hope that cell-based therapeutics may possess, at least in principle, the ability to produce anisotropic forceproducing muscle, and perhaps one day can regenerate the contractile function of adult myocardium lost during the initial pathological insult.

\section{Acknowledgments}

We thank Benjamin Van Biber for technical assistance with cell culture, Sharmon Knecht and the Fred Hutchinson Imaging Core for electron microscopy assistance, Sean Murphy for assistance with immunocytochemistry, Michael McNamara and Robin Wilson for data analysis, the UW Garvey imaging Core for use of the Nikon confocal microscope, and Marta Scatena for use of the Zeiss fluorescence microscope.
This work was supported by the NIH grants T32-GM 7266-37 S1 (S.D.L.), R01-HL111197 (M.R.), R21-HL091368 (M.R.), K08-HL80431 (M.A.L.), R01-HL064387 (M.A.L.), P01HL094374 (M.A.L.), and U01-HL09997 (M.A.L.) and by the Perkins Coie Award for Discovery (M.A.L.).

\section{Author Disclosure Statement}

S.D.L. and W.Z.Z. declare no financial conflicts. M.A.L. and M.R. are founders and equity holders in BEAT Biotherapeutics Corporation.

\section{References}

1. Laflamme MA and CE Murry. (2011). Heart regeneration. Nature 473:326-335.

2. Segers VFM and RT Lee. (2008). Stem-cell therapy for cardiac disease. Nature 451:937-942.

3. Bernstein HS and D Srivastava. (2012). Stem cell therapy for cardiac disease. Pediatr Res 71:491-499.

4. Boyle AJ, SP Schulman, JM Hare and P Oettgen. (2006). Is stem cell therapy ready for patients? Stem cell therapy for cardiac repair. Ready for the next step. Circulation 114: 339-352.

5. Laflamme MA, KY Chen, AV Naumova, V Muskheli, JA Fugate, SK Dupras, H Reinecke, C Xu, M Hassanipour, et al. (2007). Cardiomyocytes derived from human embryonic stem cells in pro-survival factors enhance function of infarcted rat hearts. Nat Biotechnol 25:1015-1024.

6. Caspi O, I Huber, I Kehat, M Habib, G Arbel, A Gepstein, L Yankelson, D Aronson, R Beyar and L Gepstein. (2007). Transplantation of human embryonic stem cell-derived cardiomyocytes improves myocardial performance in infarcted rat hearts. J Am Coll Cardiol 50:1884-1893.

7. Cao F, RA Wagner, KD Wilson, X Xie, J-D Fu, M Drukker, A Lee, RA Li, SS Gambhir, et al. (2008). Transcriptional and functional profiling of human embryonic stem cell-derived cardiomyocytes. PLoS One 3:e3474.

8. Fernandes S, AV Naumova, WZ Zhu, MA Laflamme, J Gold and CE Murry. (2010). Human embryonic stem cell-derived cardiomyocytes engraft but do not alter cardiac remodeling after chronic infarction in rats. J Mol Cell Cardiol 49:941949.

9. Snir M, I Kehat, A Gepstein, R Coleman, J Itskovitz-Eldor, E Livne and L Gepstein. (2003). Assessment of the ultrastructural and proliferative properties of human embryonic stem cell-derived cardiomyocytes. Am J Physiol Heart Circ Physiol 285:H2355-H2363.

10. Kehat I, D Kenyagin-Karsenti, M Snir, H Segev, M Amit, A Gepstein, E Livne, O Binah, J Itskovitz-Eldor and L Gepstein. (2001). Human embryonic stem cells can differentiate into myocytes with structural and functional properties of cardiomyocytes. J Clin Invest 108:407-414.

11. Liu J, DK Lieu, CW Siu, J-D Fu, HF Tse and RA Li. (2009). Facilitated maturation of $\mathrm{Ca} 2+$ handling properties of human embryonic stem cell-derived cardiomyocytes by calsequestrin expression. Am J Physiol Cell Physiol 297: C152-C159.

12. Liu J, J-D Fu, CW Siu and RA Li. (2007). Functional sarcoplasmic reticulum for calcium handling of human embryonic stem cell-derived cardiomyocytes: insights for driven maturation. Stem Cells 25:3038-3044.

13. Dolnikov K, M Shilkrut, N Zeevi-Levin, S Gerecht-Nir, M Amit, A Danon, J Itskovitz-Eldor and O Binah. (2006). 
Functional properties of human embryonic stem cell-derived cardiomyocytes: intracellular $\mathrm{Ca} 2+$ handling and the role of sarcoplasmic reticulum in the contraction. Stem Cells 24:236-245.

14. Binah O, K Dolnikov, O Sadan, M Shilkrut, N Zeevi-Levin, M Amit, A Danon and J Itskovitz-Eldor. (2007). Functional and developmental properties of human embryonic stem cells-derived cardiomyocytes. J Electrocardiol 40:S192-S196.

15. Sartiani L, E Bettiol, F Stillitano, A Mugelli, E Cerbai and ME Jaconi. (2007). Developmental changes in cardiomyocytes differentiated from human embryonic stem cells: a molecular and electrophysiological approach. Stem Cells 25:11361144.

16. Kim C, M Majdi, P Xia, KA Wei, M Talantova, S Spiering, B Nelson, M Mercola and H-SV Chen. (2010). Non-cardiomyocytes influence the electrophysiological maturation of human embryonic stem cell-derived cardiomyocytes during differentiation. Stem Cells Dev 19:783-795.

17. Földes G, M Mioulane, JS Wright, AQ Liu, P Novak, B Merkely, J Gorelik, MD Schneider, NN Ali and SE Harding. (2011). Modulation of human embryonic stem cell-derived cardiomyocyte growth: a testbed for studying human cardiac hypertrophy? J Mol Cell Cardiol 50:367-376.

18. Dolnikov K, M Shilkrut, N Zeevi-Levin, A Danon, S GerechtNir, J Itskovitz-Eldor and O Binah. (2005). Functional properties of human embryonic stem cell-derived cardiomyocytes. Ann N Y Acad Sci 1047:66-75.

19. Pillekamp F, M Reppel, O Rubenchyk, K Pfannkuche, M Matzkies, W Bloch, N Sreeram, K Brockmeier and J Hescheler. (2007). Force measurements of human embryonic stem cell-derived cardiomyocytes in an in vitro transplantation model. Stem Cells 25:174-180.

20. Zhu W-Z, Y Xie, KW Moyes, JD Gold, B Askari and MA Laflamme. (2010). Neuregulin/ErbB signaling regulates cardiac subtype specification in differentiating human embryonic stem cells. Circ Res 107:776-786.

21. Steven Korte F, J Dai, K Buckley, ER Feest, N Adamek, MA Geeves, CE Murry and M Regnier. (2011). Upregulation of cardiomyocyte ribonucleotide reductase increases intracellular 2 deoxy-ATP, contractility, and relaxation. J Mol Cell Cardiol 51:894-901.

22. Olivetti G, E Cigola, R Maestri, D Corradi, C Lagrasta, SR Gambert and P Anversa. (1996). Aging, cardiac hypertrophy and ischemic cardiomyopathy do not affect the proportion of mononucleated and multinucleated myocytes in the human heart. J Mol Cell Cardiol 28:1463-1477.

23. Schmid G and P Pfitzer. (1985). Mitoses and binucleated cells in perinatal human hearts. Virchows Arch B Cell Pathol 48:59-67.

24. Dabiri GA, KK Turnacioglu, JM Sanger and JW Sanger. (1997). Myofibrillogenesis visualized in living embryonic cardiomyocytes. Proc Natl Acad Sci U S A 94:9493-9498.

25. Stout AL, J Wang, JM Sanger and JW Sanger. (2008). Tracking changes in Z-band organization during myofibrillogenesis with FRET imaging. Cell Motil Cytoskeleton 65:353-367.

26. Korte FS and KS McDonald. (2007). Sarcomere length dependence of rat skinned cardiac myocyte mechanical properties: dependence on myosin heavy chain. J Physiol (Lond) 581:725-739.

27. Pillekamp F, M Haustein, M Khalil, M Emmelheinz, R Nazzal, R Adelmann, F Nguemo, O Rubenchyk, K Pfannkuche, et al. (2012). Contractile properties of early human embryonic stem cell-derived cardiomyocytes: beta-adrener- gic stimulation induces positive chronotropy and lusitropy but not inotropy. Stem Cells Dev 21:2111-2121.

28. Norström A, K Akesson, T Hardarson, L Hamberger, P Björquist and P Sartipy. (2006). Molecular and pharmacological properties of human embryonic stem cell-derived cardiomyocytes. Exp Biol Med (Maywood) 231:1753-1762.

29. Laflamme MA, J Gold, C Xu, M Hassanipour, E Rosler, S Police, V Muskheli and CE Murry. (2005). Formation of human myocardium in the rat heart from human embryonic stem cells. Am J Pathol 167:663-671.

30. Kehat I, L Khimovich, O Caspi, A Gepstein, R Shofti, G Arbel, I Huber, J Satin, J Itskovitz-Eldor and L Gepstein. (2004). Electromechanical integration of cardiomyocytes derived from human embryonic stem cells. Nat Biotechnol 22:1282-1289.

31. Dai W, LJ Field, M Rubart, S Reuter, SL Hale, R Zweigerdt, RE Graichen, GL Kay, AJ Jyrala, et al. (2007). Survival and maturation of human embryonic stem cell-derived cardiomyocytes in rat hearts. J Mol Cell Cardiol 43:504-516.

32. van Laake LW, R Passier, J Monshouwer-Kloots, AJ Verkleij, DJ Lips, C Freund, K den Ouden, D Ward-van Oostwaard, J Korving, et al. (2007). Human embryonic stem cell-derived cardiomyocytes survive and mature in the mouse heart and transiently improve function after myocardial infarction. Stem Cell Res 1:9-24.

33. Xu C, S Police, N Rao and MK Carpenter. (2002). Characterization and enrichment of cardiomyocytes derived from human embryonic stem cells. Circ Res 91:501-508.

34. New RB, JL Zellner, L Hebbar, R Mukherjee, AC Sampson, JW Hendrick, JR Handy, FA Crawford and FG Spinale. (1998). Isolated left ventricular myocyte contractility in patients undergoing cardiac operations. J Thorac Cardiovasc Surg 116:495-502.

35. Ou D-B, Y He, R Chen, J-W Teng, H-T Wang, D Zeng, X-T Liu, L Ding, J-Y Huang and Q-S Zheng. (2011). Threedimensional co-culture facilitates the differentiation of embryonic stem cells into mature cardiomyocytes. J Cell Biochem 112:3555-3562.

36. Zhu W-Z, LF Santana and MA Laflamme. (2009). Local control of excitation-contraction coupling in human embryonic stem cell-derived cardiomyocytes. PLoS One 4:e5407.

37. Lieu DK, J Liu, CW Siu, GP McNerney, HF Tse, A AbuKhalil, T Huser and RA Li. (2009). Absence of transverse tubules contributes to non-uniform $\mathrm{Ca}(2+)$ wavefronts in mouse and human embryonic stem cell-derived cardiomyocytes. Stem Cells Dev 18:1493-1500.

38. Baharvand H, M Azarnia, K Parivar and SK Ashtiani. (2005). The effect of extracellular matrix on embryonic stem cellderived cardiomyocytes. J Mol Cell Cardiol 38:495-503.

39. Satin J, I Kehat, O Caspi, I Huber, G Arbel, I Itzhaki, J Magyar, EA Schroder, I Perlman and L Gepstein. (2004). Mechanism of spontaneous excitability in human embryonic stem cell derived cardiomyocytes. J Physiol (Lond) 559: 479-496.

40. McDevitt TC, JC Angello, ML Whitney, H Reinecke, SD Hauschka, CE Murry and PS Stayton. (2002). In vitro generation of differentiated cardiac myofibers on micropatterned laminin surfaces. J Biomed Mater Res 60:472-479.

41. McDevitt TC, KA Woodhouse, SD Hauschka, CE Murry and PS Stayton. (2003). Spatially organized layers of cardiomyocytes on biodegradable polyurethane films for myocardial repair. J Biomed Mater Res A 66:586-595.

42. Bursac N, KK Parker, S Iravanian and L Tung. (2002). Cardiomyocyte cultures with controlled macroscopic anisotro- 
py: a model for functional electrophysiological studies of cardiac muscle. Circ Res 91:e45-e54.

43. Kim D-H, EA Lipke, $\mathrm{P}$ Kim, R Cheong, S Thompson, $\mathrm{M}$ Delannoy, K-Y Suh, L Tung and A Levchenko. (2010). Nanoscale cues regulate the structure and function of macroscopic cardiac tissue constructs. Proc Natl Acad Sci U S A 107:565-570.

44. Kim D-H, Kshitiz, RR Smith, P Kim, EH Ahn, H-N Kim, E Marbán, K-Y Suh and A Levchenko. (2012). Nanopatterned cardiac cell patches promote stem cell niche formation and myocardial regeneration. Integr Biol (Camb) 4:1019-1033.

45. Engler AJ, C Carag-Krieger, CP Johnson, M Raab, H-Y Tang, DW Speicher, JW Sanger, JM Sanger and DE Discher. (2008). Embryonic cardiomyocytes beat best on a matrix with heartlike elasticity: scar-like rigidity inhibits beating. J Cell Sci 121:3794-3802.

46. Kita-Matsuo H, M Barcova, N Prigozhina, N Salomonis, K Wei, JG Jacot, B Nelson, S Spiering, R Haverslag, et al. (2009). Lentiviral vectors and protocols for creation of stable hESC lines for fluorescent tracking and drug resistance selection of cardiomyocytes. PLoS One 4:e5046.

47. Parker KK, J Tan, CS Chen and L Tung. (2008). Myofibrillar architecture in engineered cardiac myocytes. Circ Res 103:340-342.

48. Jacot JG, H Kita-Matsuo, KA Wei, HSV Chen, JH Omens, M Mercola and AD McCulloch. (2010). Cardiac myocyte force development during differentiation and maturation. Ann N Y Acad Sci 1188:121-127.

49. Rodriguez AG, SJ Han, M Regnier and NJ Sniadecki. (2011). Substrate stiffness increases twitch power of neonatal cardiomyocytes in correlation with changes in myofibril structure and intracellular calcium. Biophys J 101:2455-2464.

50. Hazeltine LB, CS Simmons, MR Salick, X Lian, MG Badur, W Han, SM Delgado, T Wakatsuki, WC Crone, BL Pruitt and SP Palecek. (2012). Effects of substrate mechanics on contractility of cardiomyocytes generated from human pluripotent stem cells. Int J Cell Biol 2012:508294.

51. Sparrow JC and F Schöck. (2009). The initial steps of myofibril assembly: integrins pave the way. Nat Rev Mol Cell Biol 10:293-298.

Address correspondence to: Dr. Michael A. Laflamme Department of Pathology

Center for Cardiovascular Biology Institute for Stem Cell \& Regenerative Medicine University of Washington Box 358050

850 Republican Street Seattle, WA 98109

E-mail: laflamme@u.washington.edu

Dr. Michael Regnier Department of Bioengineering Institute for Stem Cell and Regenerative Medicine University of Washington Box 358056

850 Republican Street Seattle, WA 98109

E-mail: mregnier@u.washington.edu

Received for publication September 7, 2012

Accepted after revision March 1, 2013

Prepublished on Liebert Instant Online March 6, 2013 